\section{Pisacano Leadership Foundation Selects Its Class of 2004 Scholars}

The Pisacano Leadership Foundation, the philanthropic arm of the American Board of Family Medicine (ABFM), recently selected its Pisacano Scholars Class of 2004. These 5 medical students follow in the footsteps of 46 Scholar Alumni who are practicing physicians and 20 current Scholars who are attending medical school or are enrolled in Family Medicine residencies across the country. Since its founding in 1993, the Pisacano Leadership Foundation has selected students who exhibit the qualities that typify the vision and legacy of Nicholas J. Pisacano, MD, the ABFM's founder and first Executive Director. Each Pisacano Scholar has demonstrated the highest level of scholarship, leadership, character, interpersonal skills, and community service. The following are summaries of the academic and personal accomplishments of each member of the Pisacano Scholars Class of 2004.

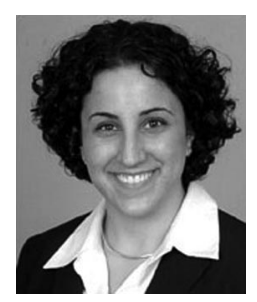

Molly Cohen is a fourth-year medical student at the University of Medicine and Dentistry of New Jersey, Robert Wood Johnson Medical School (UMDNJ). She received her Bachelor of Arts in Biology at Rutgers College, graduating with highest honors from the General Honors Program. Molly was one of 11 Rutgers sophomores accepted into a 7-year joint BA/MD program through Rutgers University and the Robert Wood Johnson Medical School, completing her first year of medical school during her junior and senior years of college. She was inducted into the Phi Beta Kappa and Phi Eta Sigma national honor societies and was a member of the Dean's list all 8 semesters at Rutgers. On graduation, Molly was awarded the S. Oakley Van Der Poel Award, given to members of the graduating class of 2002 who intended to study medicine and who demonstrated exceptional proficiency in bacteriology and medical chemistry. During medical school, as the Homeless Project Coordinator for the Homeless and Indigent Population Health care Outreach Project (HIPHOP), Molly founded "Project HIPHOP," a program that provides medical students and physician assistant students with general volunteer opportunities in the New Bruns- wick community. In 2003, Molly was elected to the position of Student Director of the Healthcare Outreach Project (HOP) Clinic at UMDNJ, overseeing 47 student doctors who are the primary service providers for the clinic's uninsured patients, and helped obtain full coverage for the clinic's patients. In recognition of her work at the clinic, Molly received the American Academy of Family Physicians (AAFP) Student Community Outreach Award at the 2004 National Convention in Kansas City. Molly looks forward to opening her own practice in an urban underserved area to combine physical healing with psychological and social care as a means of providing holistic treatment for her patients.

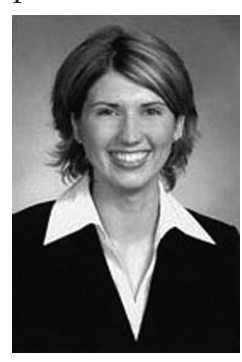

Jessica Dingman is a fourthyear medical student at Loyola University Chicago Stritch School of Medicine. She graduated magna cum laude from the University of Notre Dame with a Bachelor of Arts in Anthropology. Jessica was named a Notre Dame Scholar during her freshman year and was a member of the Dean's honor list all semesters in college. Jessica was also very involved in the community, volunteering at a hospital and health clinic as a patient advocate. Jessica has continued her academic excellence, leadership, and community service throughout medical school. She was awarded the John R. Tobin Scholarship earlier this year. This award is given to one senior student demonstrating outstanding leadership, scholarship, and adherence to Judeo-Christian ethical principles. She was also recently inducted into Alpha Sigma $\mathrm{Nu}$, a National Jesuit Honor Society, reserved for no more than $4 \%$ of the class. Jessica is currently the Student President of the Illinois Academy of Family Physicians, serving on 2 of its committees. She is also the Student Membership Liaison for the AAFP and the Secretary for Loyola's class of 2005. During the summer between her first and second year of medical school, Jessica participated in a medical mission trip to Haiti, where she provided patient care in a small village-a trip she describes as memorable and lifechanging. As a family physician, Jessica envisions herself practicing the full spectrum of patient care 
while continuing to volunteer time at free clinics or incorporating care for the underinsured into her own practice.

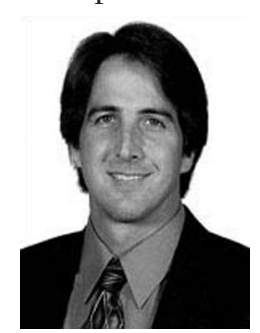

James Dolan is a fourth-year medical student at the University of Michigan (UM) Medical School. He also completed his undergraduate studies at UM, graduating with a double major in history and French. James has been accepted into a Master of Public Health (MPH) program at UM's School of Public Health. Before beginning medical school, James traveled internationally for 11 years as a teacher and as a volunteer and employee for Habitat for Humanity. He has taught in Korea, the Caribbean, Ecuador, Costa Rica, and Michigan. James also served as a coach for a number of high school and youth soccer teams during this time. He has led 3 Habitat for Humanity work teams on international service projects to the Philippines, Costa Rica, and El Salvador. James most recently worked in Costa Rica for 2 years as a Community Development Consultant for Habitat for Humanity. As a medical student, James has continued his exceptional leadership and community service. He cochaired the La Mesa Redonda, which is a group of medical students interested in furthering their spoken Spanish abilities, with the idea of helping serve an ever-increasing Hispanic population here in the United States. In addition, James volunteered with 2 migrant clinics. During the summer after his first year of medical school, he participated in a mission trip to a hospital in Haiti. He and the other 4 medical students on his team won the inaugural Midwest Medwar, as they covered 15 miles on foot and canoe, and dealt with simulated medical emergencies and navigational puzzles along the way. Most recently, James started a Wilderness Medicine student interest group, of which he is co-chair. As a family physician, James envisions working internationally in a capacity that will allow him to fulfill his humanitarian mission.

Oswaldo Grenardo, a 2004

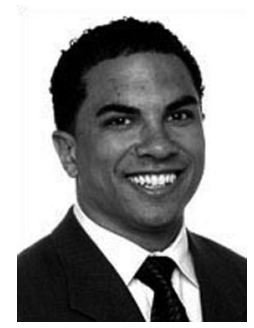
Pisacano Scholar, is a fourthyear medical student at the University of Colorado School of Medicine. Oswaldo graduated from Stanford University with a Bachelor of Arts in Human Biology, where he also earned a full football scholarship. He received a Master's degree in Health Administration and an MBA from the University of Colorado. Immediately after college, Oswaldo and a partner started their own business selling lecture notes to students at Colorado State University, managing over 30 employees. During this time, Oswaldo also created an annual alumni basketball tournament at his former high school, which provides scholarship money to underprivileged high school students. As the president of the Colorado Minority Health Forum, Oswaldo helped the Forum position itself to be the state leader in terms of promoting diversity in health care. In recognition of these efforts, he was named to 2 prestigious committees that were chosen by the Governor of Colorado and the Executive Director of the Colorado Department of Health and Environment: the State Tobacco Education and Prevention Partnership Advisory Board and the Colorado Turning Point Initiative. As a medical student, Oswaldo has continued his remarkable leadership and community service. He currently works as an independent consultant, analyzing and negotiating managed care contracts for several medical providers. The Dean of the medical school named him as the first Dean's Diversity Scholar, based on his interests in collaborative planning and utilization of resources toward racial and ethnic student recruitment and retention efforts. He is a member of the Student National Medical Association, the Colorado Medical Society Student Chapter and Colorado's Family Medicine Interest Group. As a family physician, Oswaldo hopes to have a small practice and to be engaged in activities that encompass all aspects of patient care.

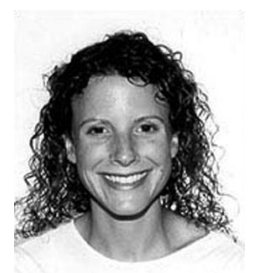

Eleni Spartos O'Donovan is a fourth-year medical student at the University of Massachusetts Medical School (UMass). She graduated magna cum laude with a Bachelor of Arts in Medieval and Renaissance Studies from New York University (NYU). She was a 3-year member of the Dean's Scholars Program, a scholarship program focused on cross-cultural awareness and community service. Eleni was awarded the NYU Marco Polo Club Award for Excellence in Medieval Studies and NYU's Schuchard Anniversary Prize in German Literature. In addition, Eleni was the captain of NYU's Women's Varsity Fencing Team her senior year and received 
an NYU Scholar-Athlete Award at graduation. After graduating from NYU, Eleni taught high school English for 4 years and was also the girls' varsity head track coach for 2 of those years. During her second year of teaching, she wrote a grant to obtain funding from a local organization to start a health and wellness resource center at the high school. Her efforts led to the foundation of the Swampscott High Prevention Center. Before beginning medical school, Eleni received her Master's in Maternal and Child Health from the Harvard School of Public Health. She became a Boston Schweitzer Fellow during her second year of graduate school and completed a yearlong service project for the fellowship with the Youth Outreach Program of the Sierra Club. As a second-year medical student, Eleni started a new elective course in teen pregnancy. She was elected to UMass' 4-year Pathways Program, a program for students focused on building cultural competence, foreign language skills, and community service projects with minority communities. Her peers recognized her contributions last year when she received a Student Body Committee Leadership Award. Most recently, Eleni completed a 6-week health policy elective in the health committee office of Senator Edward Kennedy. As a National Health Service Corps Table 1. 2005 Examination Dates
Scholar, and through her previous experiences, Eleni plans on making her future professional home in a community health center.

\section{Number of Exam Dates and Testing Centers Increased for $\mathbf{2 0 0 5}$}

The American Board of Family Medicine (ABFM) will administer its Certification/Recertification, Sports Medicine, and Adolescent Medicine Examinations exclusively on computer in 2005. The Certification/Recertification and Geriatric Certification Exams will require 1 day and Sports Medicine, Adolescent Medicine, and Geriatric Recertification will require a half-day.

Certificiation/Recertification, Sports Medicine, Geriatric (Cert/Recert) will be conveniently offered at more than 200 locations throughout the United States (Fig. 6). (Adolescent Medicine locations were not available at deadline.)

The number of exam dates has been increased to be conveniently offered on selected Thursdays, Fridays, and Saturdays (Table 1). Expanded availability of dates and locations will help reduce the candidate's loss of income from practice, travel and lodging expenses, and provide earlier results. For more information, please contact the Help Desk at 1-877-221-7437.

\begin{tabular}{lcr}
\hline Certification, Recertification, and Sports Medicine & Geriatric Medicine & Adolescent Medicine \\
\hline Thursday, Friday, or Saturday & Wednesday & Thursday \\
July 21, 22, 23, 28, 29,30 & November 2 & December 1 \\
August 4, 5,6 & & \\
December $2,{ }^{*}$ & & \\
\hline
\end{tabular}

* Limited eligibility—off-cycle residents, candidates with extraordinary circumstances precluding them from taking the July/August exam, and candidates who are unsuccessful on the July/August exam. 

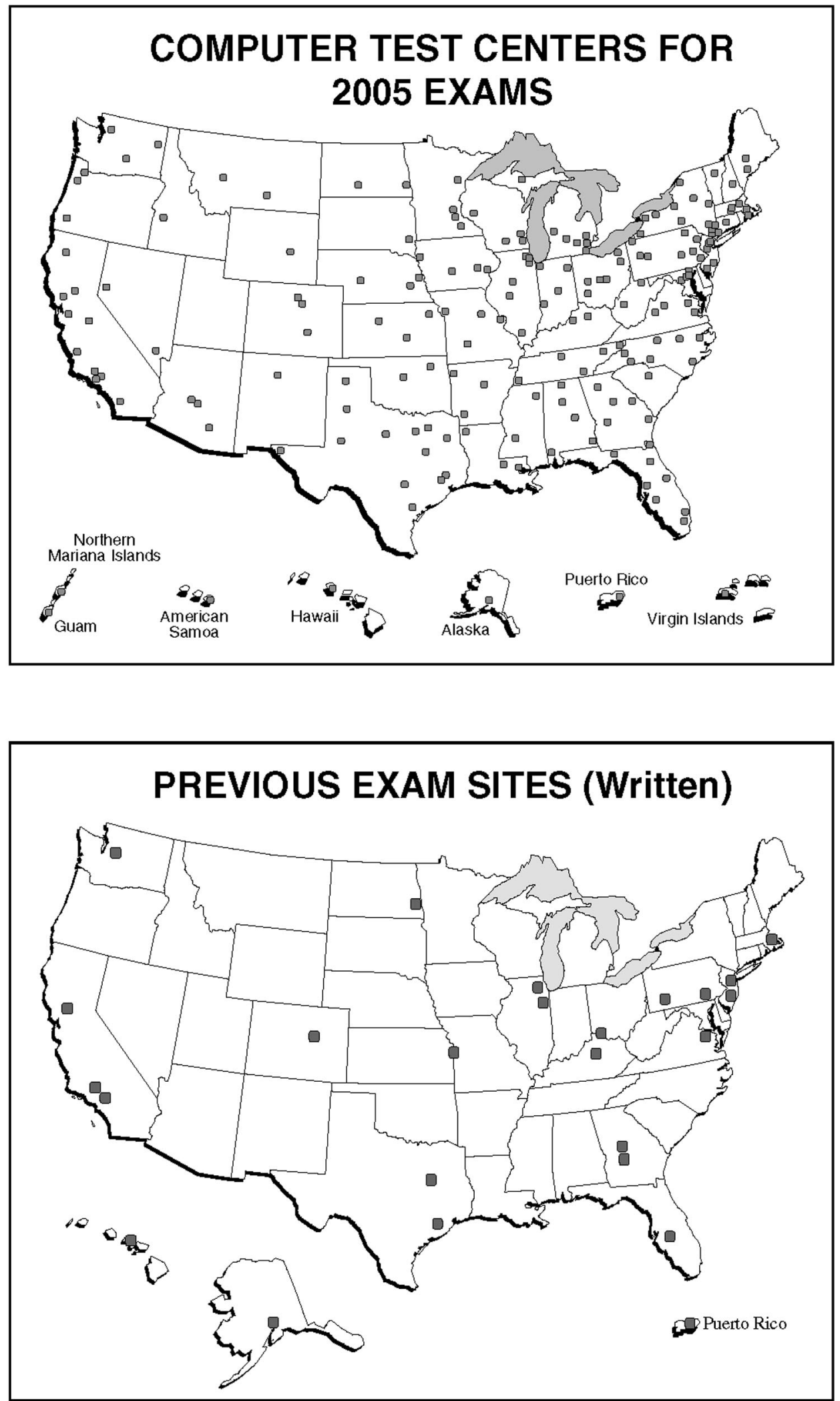

Figure 6. Test locations. 